\title{
HELPING STUDENTS PREPARE FOR MICROSOFT OFFICE SPECIALIST CERTIFICATION EXAMS
}

\author{
Thomas L. Ngo-Ye, Alabama State University, tngoye@alasu.edu \\ Jae J. Choi, Pittsburg State University, jchoi@pittstate.edu \\ Dexter Gittens, Alabama State University, dgittens@alasu.edu
}

\begin{abstract}
Microsoft Office is an important skill for all business major students, and this skill is demanded by many employers. Microsoft Office specialist (MOS) Certification issued by Microsoft, validates one's skills in Office Productivity Applications and provides objective proof of the individual's mastery of such skills. In this paper, we report how we teach and help students to pass MOS Certification exams. We also share our experience of undertaking the MOS Certification Exam program at our institution. We provide detailed steps and tips for implementing this program. This study will help other faculties who are considering implementing the MOS program identify what to expect, and pitfalls to avoid. Overall, we believe that the MOS program is beneficial to students because it provides technical credential, boost their computer self-efficacy, and improve their career perspective. MOS program is also useful for higher education institutions because it provides an objective metric to demonstrate the added value of the higher education.
\end{abstract}

Keywords: Microsoft Office Specialist (MOS), Certification Exam, Help Students Prepare MOS Certification Exam, Become a Certiport Authorized Testing Center (CATC)

\section{INTRODUCTION}

In modern society, information technology (IT) has become an indispensable part of personal, social, and professional life. Currently, more than $50 \%$ of jobs require some technology skills, and the percentage will grow to $77 \%$ in the next decade as predicted by experts (Microsoft, 2018). Basic computer skills such as Microsoft Office are required for both academic success and professional career success (Ngo-Ye \& Choi, 2015). According to a recent report commissioned by Microsoft, Microsoft Office proficiency is one of the most requested skills students need for the top high-growth and high-wage jobs (Microsoft, 2018). In fact, Microsoft Office is the only software appearing in the top 20 skill list required for high-growth and high-wage positions. Employers surveyed by McKinsey/Manpower indicated that they have the highest talent deficiency since 2007 (Manpower Group, 2017). More than 50\% of employers expressed that they are very challenged to find IT-qualified employee who are comfortable and competent in the Microsoft Office.

While around $72 \%$ of colleges believe their new graduates are ready to enter the workforce, only $42 \%$ of employers agree that graduates are actually ready for the jobs. In other words, there is a big disconnect between reality and expectations on computer literacy skills (IDC, 2012). In recent years, the demand for computer literate and certified job candidates has grown by $26 \%$ annually (IDC, 2012). The main reason employers cannot fill open positions is because job candidates lack the training and certification needed.

In general, IT certification helps an individual's career advancement, promotion and pay raise (Pearson, 2016). To address the above issue of Microsoft Office talent gap and better equip our business students for the job market, we initiated the endeavor to help students pass Microsoft Office Specialist certification exams. Microsoft Office Specialist (MOS) certification is issued by Microsoft and recognized in the industry. Overall, IT certification tends to help students enhance their professional image and boost their marketability (Ngo-Ye \& Choi, 2016).

In this paper, we first present the research question and research methodology. Next, we describe what is Microsoft Office Specialist certification and its benefits. Then we highlight what we have done to help students pass the MOS certification exams. Next, we report how we implement the Microsoft Office Specialist (MOS) certification exam program at our institution. Then we present the important lessons learned in this initiative. By sharing our first-hand 
experience with the MOS certification exam program, we hope this study helps fellow IS faculties in their pursuit of assisting students to pass MOS certification exams.

\section{RESEARCH QUESTION AND METHODOLOGY}

This research centers upon the following research questions: 1) How to better prepare students for passing Microsoft Office Specialist certification exams? 2) How to better administer Microsoft Office Specialist certification exams?

Based on the nature of our research questions, we undertook this study with a qualitative research method observational case study in a natural setting. We systematically categorized, described, and analyzed our interactions with students on preparing them for MOS certification exams, and administering MOS certification exams based on our empirical classroom observations. We carried out this study in a small university in the south east region of the United States of America. The observation subjects are undergraduate students enrolled in an Introduction to Computer class over the course of the previous one and half years. We made careful classroom observations and engaged in informal conversations with students after they finished the MOS certification exams. In this paper, we attempt to be as objective as possible in documenting the observed facts and presenting the gained insights.

\section{MICROSOFT OFFICE SPECIALIST CERTIFICATION}

According to Microsoft, MOS certification is for people looking to showcase their proficiency in one or more Microsoft Office applications. MOS certification is the leading credential selected by people aiming to validate their Microsoft Office skills and enhance their professional careers. MOS certification is also a great instrument for assessing student skills and preparing them for real-world application. When an individual passes a particular MOS certification exam, such as Excel 2016, he/she is certified in that passing application, Excel 2016 in this case. A person can pass multiple MOS certification exams on different applications, such as Word 2016, PowerPoint 2016, Excel 2016, and Access 2016, and obtain multiple certifications, one for each application exam passed.

\section{The Format of MOS Certification Exam}

For a MOS certification exam on an application such as PowerPoint, the time limit is 50 minutes. Before the real exam starts, exam takers can take their time to walk through the tutorial to get familiar with the MOS certification exam software. The time spent on the tutorial does not count toward the 50 minute time limit.

Instead of using multiple choice questions as in many IT certification exams, a MOS certification exam is composed of solely performance-based questions. A performance-based question means that based on the exam instruction, an exam taker needs to use the mouse to click here and there in the simulated Office application and use the keyboard to make some entries in the application, for example, "Apply cell style Neutral to range A1 to H1". The exam includes about 35 such performance-based questions. The questions are divided into multiple sections, each concentrating on a particular knowledge point, such as, import an xml file into Access database or modifying an SQL query. Together these questions cover many techniques in the use of Office Application. The questions are realistic and based on realworld cases. Exam takers are prompted to complete a series of tasks to evidently prove their skills in an Office application. MOS certification exams ask a test taker to build a project, with tasks and steps that build on each other. Overall, this project-based testing for MOS certification exam offers industry-premiere evaluations of skills and knowledge, giving students real-world exercises to assess their proficiency of Microsoft Office. MOS certification exams are conducted in a simulated Microsoft Office environment. The simulated Office application has almost all features of a real Office application. A main difference between the simulated and real Office application is that we cannot use File - Open to access the real file directory on the exam PC. We can only access what the MOS exam provides and presents to us, for example, a comma delimited text file to be imported into the Excel document as part of the exam question. In the simulated Office application, we can save the file as exam instruction directs us to do so.

\section{Logistics of MOS Certification Exam}

Students should contact a local Certiport (http://www.certiport.com) office to find out where to take the MOS certificate exam and how much are the fees for taking the exam. According to Microsoft, all Microsoft Office Specialist certification exams are administered by Certiport, which is the premiere certification organization endorsed 
by Microsoft. After an individual completes a MOS certification exam, the exam result is immediately shown on the exam PC screen. The exam taker can see whether he/she passes or fails the exam, his/her total score, and the breakdown of section scores. The perfect score for a MOS certification exam is 1000 and the required passing score is 700. An exam taker can also login http://www.certiport.com and click the link "My Transcript" to view and download exam score report in PDF format. If an exam taker passes an exam, he/she can also download the MOS certification in PDF format under "My Transcript".

\section{MOS Exam Retake Policy}

According to Certiport, if an exam taker fails an exam (with score bellow 700) the first time, the individual must wait 24 hours before retaking the exam. If an exam taker fails the second time, he/she has to wait 2 days ( 48 hours) before retaking the exam a third time. A 48 hour waiting period will be enforced for each subsequent exam retake. An exam taker can make an unlimited number of attempts on the same exam.

\section{Benefits of MOS Certification}

MOS is an industry-recognized certification which helps students to build a successful future. Preparing for MOS certification exam helps students learn the technical skills employers are looking for and therefore boost their résumé profile. Furthermore, it helps students gain valuable experience and self-confidence. MOS certification can be empowering for students and educators. Overall, MOS certification benefits students that earn the certifications, the IS program helping students to obtain the certifications, and the higher education institution that implements the MOS certification program. For a student passing an MOS certification exam, it demonstrates that the student has the skills in a specific Office application. The MOS credential allows individuals to validate their skills and progress toward their future professional career goals.

Not only useful in an academic setting, the MOS certification also helps enhance students' career prospects by giving them a competitive edge in the job market. Once students pass a MOS certification exam, they are encouraged to include their Microsoft Office Specialist credential on their résumé. MOS certifications show to potential employers that students have proven, comprehensive proficiency in Microsoft Office applications. Moreover, MOS certification demonstrates that students have mastered the skills to take advantage of the full features and functionality of Microsoft Office. Students who acquire MOS certification have proven competency in Office skills and enhance personal confidence in computer skills, and thus differentiate themselves from other job applicants who lack suck skills. MOS certification also helps to enhance students' academic performance and prepares students for their future professional careers. For people who pass a MOS certification exam, they also earn a digital badge that is awarded for display in their résumé, social media profiles, and email signature. Achieving MOS certification heightens students' earning potential as entry-level business employees (Anderson \& Gantz, 2013).

Helping students achieving MOS certification also benefits the IS department and its programs. The MOS certification can be served as an objective external measure to demonstrate students' learning outcome with regards to Microsoft Office. It will be useful for higher education institutions applying for accreditation because it enhances academic results.

\section{HOW DO WE (FACULTY) HELP STUDENTS PREPARE MOS CERTIFICATION EXAMS}

Before we start helping our students prepare for MOS certification exams, we first attempted MOS certification exams ourselves. As IS faculty, we are already very familiar with Microsoft Office from our teaching and work experiences. To improve our chances of passing MOS certification exams, we also watch some relevant YouTube videos on how to prepare for MOS certification exams. Subsequently, we took the real MOS certification exams and passed Word 2013, PowerPoint 2013, Excel 2013, and Access 2013 exams. With this recent first-hand experience, we created hands-on practice Excel and Access projects that cover many of the knowledge points that appeared in the MOS certification exams. We then tutored students on Excel and Access in our Introduction to Computer class. This is required for all business major students.

With regards to the teaching method for training students for MOS certification exams, we adopted the popular approach of "I, we, and you". "I" means that instructors lecture and demonstrate on the big projector screen how to perform the tasks. After the mini-lecture and demonstration for one task or partial task of the practice project, students 
are asked to follow the instructor on the same steps. This is the "we" part, where students and the instructor work together on the project. Finally, in the "you" part, students are asked to work independently on the project and the instructor does not perform any lecture or demonstration. The goal of the "you" part is to encourage students to test their own skills and see if they can solve the problems independently. However, when students encountered issues, the instructor would help students individually by showing them how to address the task.

As instructors, we pay close attention to students' progress on MOS certification practice projects. Consistent with the study reported in the literature (Ngo-Ye, 2017), we notice that some students struggle with file and folder operations, based on our first-hand classroom observations. Our solution was to post the practice project files (Excel or Access files) on Blackboard and then ask students to download them to their PC. Then we asked students to open the downloaded file and use "Save As" to save it with a new file name containing their full name. Moreover, we instructed students to save the new file on their desktop so that they can locate their project file. Fortunately, the real MOS certification exams focus on testing people's proficiency in Office applications, not file and folder operation skills. The most important file/folder related operation in the test is to locate a file (a photo, a text document, or an XML document) from a folder and insert/import into the current document. Another important skill is to save the Office document.

Besides the features and functionalities of Office applications, we noticed that some students had difficulty with some rudimentary computer operations, just as reported in prior studies (Ngo-Ye \& Choi, 2015). More specifically, some students struggled with selecting a range of multiple continuous cells in Excel. To solve this problem, we asked students to not use the mouse, which is very tricky for novice computer users. Instead we demonstrated how to use "Shift" key and "Right and/or Down Arrow" keys to highlight a range of cells. This method of using keys on keyboard seems work very well for students. It avoids many mistakes novice computer users make with the mouse. We also noticed that many students did not know how to select a row/column, or multiple continuous rows/columns. To solve this problem, we demonstrated how to move the mouse to the top/left of a column/row, waiting until the cursor changed to the shape of a solid black arrow and then left-clicking the mouse. In this way, students learned how to highlight a row or column. We observed that some students only select a range of cells, rather than a row/column as instructed. Then we explained the difference between a range of cells and the whole row/column. After the students had mastered the skill of highlighting a single row and column, we demonstrated how to select multiple continuous rows and columns using the "Shift and Arrows" keys on the keyboard.

The most difficult mouse operation is the auto-fill feature in Excel. We lectured and demonstrated that you must first highlight a range of cells as the pattern using "Shift and Arrows" keys on the keyboard. Then we showed students how to slowly move the mouse to the right-lower corner of the last cell in the range and watch the cursor change shape to a solid cross. Then we left clicked mouse, pressed and held the left button, then dragged slowly to the end of the target range, and finally released the mouse. It took multiple practices for students to master these critical skills. Another difficult knowledge point is absolute reference. We demonstrated to students how to manually add " $\$$ " in front of a cell's row and column index. Another often ignored knowledge point is that after entering data in a cell in Excel, students need to press "Enter" key on keyboard, or click the "check" icon in Excel to conclude the entry. Many students are not aware of this and bungle the Excel document.

\section{IMPLEMENTING MOS CERTIFICATION EXAM PROGRAM}

We initiated the MOS certification exam program at our college in November 2016. The primary goal of the program is to help business school students achieve MOS certifications to improve their career prospective. On the one hand, we tutored students on the subject matter of Microsoft Office skills. To motivate students to study hard and pass MOS certification exams, we provided incentives to students. We made it a mandatory requirement for every business student to take MOS certification exams (Excel and Access) in certain courses. Students can make unlimited number of attempts to take MOS certification exams and the highest exam score for each subject (Excel and Access) will be taken as the final score. On the other hand, we also sought ways to lower the cost for students to take MOS certification exams and make it convenient for students to take the exams.

We contacted Certiport and requested our university to become a Certiport Authorized Testing Center (CATC). After being verified by Certiport, our campus became a CATC. We registered a Certiport account with the roles of 
institutional administrator and MOS certification exam proctor. If our university was not a CATC, then our students would have had to physically visit a local Certiport testing site and pay the full price for a MOS certification exam. The regular full price is around $\$ 100$ per exam. When a student takes the same MOS certification exam in our university, the cost for student is only $\$ 10$ per exam and he/she can take the exam in the designated computer classroom. Therefore, it is much cheaper and convenient for students to take the exam at our university.

To make this good deal for students happen, we worked with Certiport and purchased the campus license. The campus license caters to higher education institutions. With the MOS Campus License, universities can administer exams per campus. The once-a-year fee for a Certiport campus license is $\$ 5,000$. It allows 500 exam attempts within one year from the date that the program begins. At the end of one year, the campus license expires and those unused exam attempts will be wasted. Therefore, we routinely monitor the exam attempts used by our students from http://www.certiport.com. The campus license arrangement is affordable for students $(\$ 5,000 / 500=\$ 10$ per exam attempt).

We worked out the logistics of the MOS certification exam program at our university. We convinced the university administrator to put forward $\$ 5,000$ to purchase the Certiport campus license. Because it is a fixed annual fee, it is easier for the budget process and we only need the fiscal approval once a year. We set up a university account to collect student fee of $\$ 10$ for each exam attempt. The collected students' testing fees will replenish the account for the next cycle year of MOS certification exam testing. Before a student takes the MOS certification exam, he/she has to turn in the university receipt that proves that he/she has paid $\$ 10$ for the exam attempt. After confirming the payment, an exam proctor (an instructor) will type in the proctor user name and password to proceed to the exam. With Certiport campus license, instructors can test and certify that everything works well before students take the same exam.

We chose a computer classroom as the sole Certiport testing place on our campus to administer MOS certification exams. The computer lab has 25 desktop Windows PCs. We downloaded the Certiport testing software - Console 8 , from http://www.certiport.com. It is a Windows desktop program. Then we attempted to install Certiport Console 8 on each PC in the lab. In normal computer labs at our university, the regular login for computers does not have the administrator privilege and cannot install any program. Moreover, the university IT department applies the "Deep Freeze" software, which restores the computer back to the saved configuration image when the computer is restarted at midnight every day. With "Deep Freeze" active on all PCs in the computer labs, the computers are protected from unauthorized changes. Because of a lack of the administrator privilege and the state of "Deep Freeze", we cannot install Certiport Console 8 by ourselves in the computer lab. Therefore, we worked with the university IT department and got Console 8 installed. However, to run Console 8 for MOS certification exam testing, the login must have the local administrator privilege. Therefore, we requested the university IT department to give special permission to this designated computer lab to allow the regular login to have the local administrator privilege so that Console 8 can run smoothly. After installing Console 8 software, we ran Console 8 and login with the Certiport CATC administrator/proctor account. We manually associated each PC in the lab at our university as a new CATC, in Console 8. Next, we downloaded the test banks for MOS certification exams and updated the test banks from inside Console 8. Finally, the physical testing environment was set up correctly and functioned well. For the convenience of our students, we dedicated some class meetings for MOS certification exams. We also made the arrangement that the classes requiring MOS certification exams were held in the designated computer classroom so that students can take MOS exams in the same classroom at regular class meeting time. We also hosted additional MOS certification exams tutoring and testing sessions outside regular class meeting time in the same computer classroom. In this way, students can have more chances to take the exams.

To streamline the business process of administering MOS certification exams, we developed a procedure for instructors who would administer the MOS exams. We also created a procedure/policy for students to take MOS certification exams. Next, we present these two procedures. 


\section{Procedure to Administer Microsoft Office Specialist (MOS) Certification Exams at Computer Classroom BA 110 \\ Dear Instructors:}

Right now only BA 110 has PCs with working Microsoft Certification Exam Testing Software Certiport Console 8 . So if you want to have your students to take the certification exam test now, you have to get access to BA 110.

1. Ask your students to pay $\$ 10$ to Cashier's office in student union and bring the receipt to you. Student pay to account number XXXXXX., You can give a Microsoft Certification Exam to a student only after you have the receipt

2. In BA 110, ask students to double click the icon "Console 8 " on desktop to login, if he/she has taken the certification exam before. If a student is taking Microsoft Certification exam for the first time, he/she needs to register a new account. Make sure students write down their user name and password in their smart phone note. In the past, many certification exam takers forgot their own user name and password.

3. Click "Study/Practice/Certify" (green button) in Console 8 -- Then click "Certify" button -- Then click "Microsoft Office Specialist" button -- Then click "2013" button -- Select Excel or Access. Next, students will need to verify their mailing address and check all areas of their information. Students also need to agree on the contact term before taking the exam. Students need to click three purple arrows to confirm above items.

4. After registration, you (as an instructor) need to type in proctor user name and password:

User name: $\operatorname{xxxxxx}$

Password: $\mathrm{xxxxxx}$

After instructor enters the proctor information, students can take the actual test. (Note: Please keep the proctor user name and password to yourself, not share it to students.)

5. When students complete the test, ask students to use their personal smart phone to take a picture of their exam score and their name as shown on the PC screen. Then ask students to upload that picture to Blackboard Assignments Page. Based on the uploaded exam score picture, you can give a grade on Blackboard. In the past, many students did not know their MOS exam score. Therefore, asking students to take a picture of their score is the best way to ensure having an objective exam result.

6. You need to give the receipts to the secretary of Computer Information Systems (CIS) Department for record.

Our university purchased one year 500 licenses for $\$ 5,000$. For a student, the testing fee is $\$ 10$ for each attempt of each test. The licenses will expire on Nov 22, 2017.

If you have additional question, please feel free to ask me. I will try my best to help you!

Thank you!

\section{Procedure and Policy for Taking Microsoft Office Specialist (MOS) Certification Exams at Computer Classroom BA 110}

Dear Students,

Taking Microsoft Office Specialist Access and Excel 2013 Certification Exam is mandatory! Each single attempt for a MOS certification exam costs you $\$ 10$ out-of-pocket. You need to pay this $\$ 10$ to the account \#: XXXXXX at the cashier's office at the student union. When you pay this $\$ 10$, you need to inform the cashier that you are a student, aiming to take the Microsoft Office Specialist Excel or Access 2013 certification exam. You should also tell the cashier the Microsoft Office Specialist account \#: XXXXXX. On your receipt, you should write your full name, your student ID, and account \#: XXXXXX. You must give 
the receipt to your instructor before taking a certification exam. After you take a certification exam, you must upload a copy of your own Microsoft Office Specialist Excel/Access 2013 certification exam score report to Blackboard Assignments: MOS Excel 2013 Certification Exam or MOS Access 2013 Certification Exam. Your instructor will verify your score and then give you a score for the Excel/Access exam.

Your Access/Excel Exam grade = your score of MOS certification exam of Access/Excel / 10. For example, if you got 700 in an Access certification exam, your Access exam grade will be $700 / 10=70$. Moreover, if your score is 700 or above, you passed the Microsoft Office Specialist Access/Excel 2013 certification exam. You can put your achievement of passing the Access/Excel certification exam in your resume and cover letter when you apply for jobs. If you do not take Microsoft Office Specialist Access/Excel 2013 certification exam, your score will be 0 point. You must attempt Microsoft Office Specialist Access/Excel 2013 certification exam before the last class meeting of this semester.

It is the individual student's responsibility to follow the following procedure to get the Blackboard grade for your Microsoft Office Specialist Access/Excel certification exam. Failure to follow the following procedure will result in 0 point for Access/Excel certification exam.

When you complete a Microsoft Office Specialist Access/Excel certification exam, you MUST use your personal smart phone to take a clear picture of your computer screen, which shows your Access/Excel certification exam score and your name. Then you should email the screen shot picture to your email. Next, you need to download your exam score picture from your email. Then you need to upload that picture to Blackboard Assignments Page "MOS Access/Excel Certification Exam". Based on the uploaded exam score picture, your instructor will enter the grade on Blackboard. In the past, many students did not know their certification exam score. Taking a picture of students' certification exam score on computer screen is the best way to ensure having an objective exam result.

See you soon in class.

Thank you!

\section{LESSONS LEARNED AND DISCUSSION}

From working closely with students on preparing students for MOS certification exams and actually administering the exams, we made numerous observations and gathered some valuable insights on how to better prepare students for the exams.

From our casual conversations with a convenient sample of students after exams, we learned several important lessons. First, some students did not pay attention to which Excel worksheet/Access database table to work on. Because they did not read the exam instructions carefully, they worked on the wrong sheet/table. Hence, they lost a lot of points. Second, a MOS certification exam is also a reading test. Some students did not understand the exam instructions. In other words, they could not convert the instructions into actions of keystrokes and mouse movements. In class meetings, some students merely followed the instructors' demonstrations without personal dedication to learning. Thus, some students lacked a deeper understanding of the processes. So when they were alone on a MOS certification exam, they did not know what to do. Third, some students lacked knowledge generalization. We taught students how to import an Excel file into an Access database. In MOS certification exams, a new question was to import an XML file into an Access database. Many students did not know how to handle this question. Fourth, time management in exams was a critical issue. Some students did not notice that the exam has time limit of 50 minutes, as they did not pay attention to the lecture. Some students wasted too much time on some questions so they did not complete all the questions on the exam. Fifth, it seems that a MOS certification exam is a case-based project with tasks and steps that build on previous ones. Therefore, some students were stuck at one question and then gave up on the following questions even if they might have been able to solve them individually.

To address the above issues, we modified our teaching to better accommodate the situation. One potential solution is again the teachable moment concept. Right before students starting the exam, we reiterated the importance of paying 


\section{Issues in Information Systems \\ Volume 19, Issue 4, pp. 122-131, 2018}

attention to the exam instructions regarding which worksheet/table to work on. We also stressed again the importance of time management, not wasting too much time on one question. We also demonstrated to students how to import an XML file and a text file. As for the roadblock issue of a student stuck with one question, our general suggestion before the exam was that when this situation occurred, instead of leaving it blank, one should make some reasonable guessed entries, then students can proceed to the following questions as if the entries made before were correct. We hope that the MOS exam is at least partially graded based on the formula rather than exact value. In other words, as long as students enter the correct formula in the following question, he/she may get some partial grade. It is better than leaving it totally blank by not attempting at all.

Another tip of administering MOS exam is that instructors should make sure to close all Microsoft Office applications before starting Certiport Console 8 for the test. Otherwise, it will cause Console 8 program to crash and students cannot get the exam graded. The potential reason for this is that Certiport designs the testing software in a way to check if any Office application runs parallel with Console 8. If so, there is a possibility that an exam taker is cheating. Console 8 uses the same underlying Office programs. Therefore, if Console 8 detects another instance of Office program running on the exam PC, it is an indicator of violation of exam integrity. Since Console 8 uses the same Office applications, the version of MOS certification exam must match the version of Microsoft Office installed on a PC. For example, if a PC has Office 2013 installed, we must select MOS Office 2013 for exams. In this case, we cannot have MOS Office 2016 exams on this PC.

Another general observation is that while many students failed a MOS certification exam on their very first attempt due to imperfect preparation and being unfamiliar with the exam format, many of them did manage to pass in subsequent second, third, or fourth attempts. We encouraged students to continue studying and improving their skills. We suggested students use the Skill Group performance feedback on their exam score report to determine which areas to study more. After further preparation and multiple attempts, many students did accomplish the MOS certification. Hence, perseverance is a critical element for the success at MOS certification.

We posted our written procedure and policy on how to take the MOS certification exams as announcements on Blackboard. We also discussed it with students in class meetings. We noticed that even with our effort to clarify how this business process works, many students still did not know what to do. Introducing MOS certification exams into IS curriculum increases the amount of complexity for both instructors and students. Normally, instructors design, administer, and grade the regular exams in class. Students only need to answer exam questions and write their name on the exam sheet and the instructor will give a grade without any confusion. However, with MOS certification exams from the third party - Certiport, instructors no longer grade the exam and lose direct control. Moreover, due to multiple classes requiring the same exams, Certiport website cannot provide the report for exam scores for a particular class. Certiport website only shows a report with a list of student name, date of exam, which exam, and score. There is no way to map and filter this information for a single class. Therefore, how to convey a student's exam score to an instructor is a big challenge. We designed the above procedures to mitigate the problem. However, many students still did not pay attention to the procedure that was presented in blackboard announcement and discussed in class meetings. As a result, some students forget their Certiport user name and password. Therefore, they cannot login to CErtiport Console 8 to take the exam. Moreover, many students did not follow the procedure to take a picture of the exam result screen with their personal smart phone. Therefore, there was no clear evidence what score they received. One partial solution is the idea of teachable moment. We spoke to each student immediately before they took the exam and reminded them of what they need to do. By doing so, at least some students followed the procedure.

We initially proposed two potential solutions to address the need for students to remember their Certiport user name and password: 1). Asking students to type their user name/password in their smart phone note in the registration process at Console 8. 2). Creating a new account with a different user name, while keeping everything else the same. However, even with these two ideas, some students still failed to remember what their Certiport user name and password were. Finally, we came up a final solution. We asked students to use their Blackboard user name and password as their user name and password for Certiport Console 8. Because most students use their Blackboard login regularly, they memorize this user name and password. With this practice, students no longer need to remember a new set of user name and password. The use of Blackboard user name/password as their user name/password for Certiport has mitigated a lot of issues of students forgetting their user name/password and students not knowing their exam score. It saves a lot of wasted time and frustration on the part of students. 
In the past after completing MOS exams, many students just left the computer classroom without taking a picture of the exam result screen and informing instructors of their exam score. Instructors had no way to identify the student's exam score. Because many students did not follow the procedure and did not upload the exam result screen picture from their personal smart phone to Blackboard Assignments, we developed a backup plan. Initially, we thought about asking students to Print Screen the exam result and save it as a JPEG file for record. However, we discovered that most students did not know how to do it. The final solution was to ask students to stay back after finishing a MOS exam and call the instructor for help. We helped each student by manually Print Screen, saved it as a JPEG file in the Microsoft Paint program, and then made sure the student uploads the correct JPEG file to Blackboard Assignment. We also demonstrated to students one on one how to save the JPEG file with student name as part of file name and place the JPEG file on Desktop. So that the student can locate his/her correct JPEG file on the exam PC for the purpose of uploading the exam score report to Blackboard for grade.

For students who pass a MOS certification exam, we individually helped them to login http://www.certiport.com and then click hyperlink "My Transcript", which leads to their exam score report and certification. We showed students how to download the exam score report and certification in PDF format and email them to themselves as attachments for personal record.

We've had the MOS certification exam program at our college for three semesters and many students were able to pass MOS exams. Some students indicated that they wanted to earn the MOS certifications in the near future, even if MOS exams were not required. Thus, some students do have genuine interest in MOS certifications. This positive feedback motivates us to continue advancing our MOS certification program.

\section{CONCLUSION}

Microsoft Office is a critical technical skill for business professionals beyond any doubt. Having proven credentials in Microsoft Office such as Microsoft Office Specialist Certification will enhance students' marketability and boost their computer self-efficacy. In this paper, we report our initiative of helping students to prepare for MOS certification exams. By partnering with Certiport to become a CATC, we can administer MOS certification exams on our university campus and lower the exam fee for our students. From the start of our MOS certification program until May $3^{\text {rd }}, 2018$, we have a total of 287 MOS certification exams passed by our students and faculty. Understandably, the majority of the 287 certifications are attributed to our students. On June $4^{\text {th }}, 2018$ we received a congratulation letter and a special certificate from Certiport for one of our undergraduate students winning the 2018 Microsoft Office Specialist (MOS) State Championship Spring Qualifier finishing 3rd Place in Excel 2013. This student's MOS Excel 2013 Certification Exam score is the third highest score for Excel 2013 in our state in spring 2018.

With the success of our initial stage of MOS certification program, we plan to continue improving the program and help more students achieve MOS certifications. We acknowledge that to make this MOS certification program work, it requires the financial support from university administration. It also requires the dedication of faculty to go beyond regular teaching and take on the additional responsibility of tutoring students and administering MOS certification exams for the convenience of the students. We are also impressed with many of the students, who persistently push forward toward the goal of achieving MOS certification without giving up at any initial setback. We believe that this firsthand experience is valuable to IS faculty at other institutions, who are considering implementing the MOS certification program. By sharing our lessons learned, we hope other faculties can avoid some of the issues that troubled us when we first undertook this initiative.

We acknowledge the inherent limitations of this study. At the current stage of this research project, we have not conducted a controlled experiment, and the case study is based on our interactions with students at a single university. To better gauge the effectiveness of our approach of preparing students for MOS certification exam, we plan to conduct a natural experiment. Students in some sessions of the class, as the experiment group, will be given intense instruction and tutoring as we described in this paper. Students in other sessions, as the control group, will be given regular instruction without purposeful preparation for MOS certification exams. In this way, we can compare and measure the effect of our intervention on the MOS certification exam results. Moreover, we plan to collaborate with a few local universities to implement the MOS certification program, so that we can learn from each other's experiences. With the potential larger sample size, we can better generalize the findings. We will continue documenting and distilling 
the new insight we learn from this ongoing MOS certification program. A follow-up study is scheduled to report the further findings in the future.

\section{REFERENCES}

Anderson, C., \& Gantz, J. F. (2013). Skills Requirements for Tomorrow's Best Jobs, Helping Educators Provide Students with Skills and Tools They Need. Microsoft. IDC. Retrieved May 16, 2018, from https://news.microsoft.com/download/presskits/education/docs/IDC_101513.pdf

IDC. (2012). Climate Change: Cloud's Impact On IT Organizations and Staffing. IDC.

Manpower Group. (2017). 2016-2017 Talent Shortage Survey. Retrieved May 9, 2018, from https://manpowergroup.com/talent-shortage-2016

Microsoft. (2018). Microsoft Certification Employability Evidence from Around the World. Retrieved May 9, 2018, from https://certiport.pearsonvue.com/Certifications/Microsoft/MTA/Success-stories/MicrosoftEmployability-Evidence-Brochure.pdf

Ngo-Ye, T. L. (2017). The Missing File And Folder Management Skill. The International Academy of Business and Public Administration Disciplines Conference (IABPAD 2017), (pp. 1-2). Memphis, Tennessee.

Ngo-Ye, T. L., \& Choi, J. (2015). Revisit Challenges for Teaching Computer Literacy: A Case of Using an Online Simulation Tool. Issues in Information Systems, 16(II), 226-235.

Ngo-Ye, T. L., \& Choi, J. J. (2016). Preparing Students for Security Certification: An Exploratory Experiment. Issues in Information Systems, 17(III), 59-69.

Pearson. (2016). Pearson VUE 2016 Value of IT Certification Survey. Pearson. 